\title{
Fluorine in Medicinal Chemistry: In Perspective to COVID-19
}

Cheng Zhang*

Australian Institute for Bioengineering and Nanotechnology and ARC Centre of Excellence in Convergent Bio-Nano Science and Technology, University of Queensland, Brisbane, Queensland 4072, Australia

E-mail: c.zhang3@uq.edu.au

\begin{abstract}
Over two years into the outbreak of COVID-19, the quest for effective and economical drugs has become starkly clear to reduce the risk of progression of coronavirus disease. A number of drugs have been investigated and they can be taken orally at home and be used after exposure to SARS-CoV-2 or at the first sign of COVID-19. Fluorinated oral anti-COVID-19 drugs-including Paxlovid, the first oral tablet for the treatment of COVID-19-is an important subgroup. Fluorine has been widely used in pharmaceuticals market and can lead to improved selectivity indices, increased lipophilicity, greater metabolic stability, and in this case the improved anti-COVID-19 efficacy. In this minireview, we will give an update on fluorinated anti-COVID-19 drugs by providing the key information and current knowledge of these drugs, including chemical structure, drug metabolism and pharmacokinetics, and mechanism of action.
\end{abstract}




\section{Introduction}

Coronavirus disease 2019 (COVID-19) is a contagious disease caused by severe acute respiratory syndrome coronavirus 2 (SARS-CoV-2, Figure 1). ${ }^{1}$ The disease has spread worldwide, and the threat to global health is ongoing since the first known case was identified in December 2019. As of February 23 2022, SARS-CoV-2 has caused a combined total of more than 428,196,000 confirmed infections and more than 5,925,000 reported deaths in 213 different countries. ${ }^{2}$

Starting in late 2020, numerous types of COVID-19 vaccines have been developed to protect people before they are exposed to SARS-CoV-2, providing an opportunity to restrict the transmission of the virus, and reduce the number of hospitalizations and deaths. The US Food and Drugs Administration (FDA) has approved the Pfizer-BioNTech, Moderna, and Janssen COVID-19 vaccines for emergency use in the USA, while the European Medicines Agency (EMA) also authorized the vaccine developed by AstraZeneca. ${ }^{3}$ By early 2022, 10.6 billion doses of COVID-19 vaccine have been administered around the world, mostly in high-income countries. Only $12 \%$ of people in low-income countries have received at least one dose. ${ }^{4}$ Therefore, the quest for effective and economical antiviral drugs to treat COVID-19 has been a priority since the outbreak of the disease. $^{5}$

Several direct-acting small-molecule SARS-CoV-2 antiviral drugs have been developed to treat COVID-19. These drugs have received approval or under emergency use authorization, and can be used after exposure to SARS-CoV-2 or at the first sign of COVID-19. They can be divided into two groups: 1) agents that target proteins or RNA of the virus (e.g. viral RNA-dependent RNA polymerase ( $\mathrm{RdRp})$, viral main protease ( $\mathrm{M}^{\text {pro }}$ or $\left.3 \mathrm{CL}^{\mathrm{pro}}\right)$, and etc.); 2) drugs that target host proteins (e.g. angiotensin converting enzyme-2 (ACE-2), transmembrane protease serine 2 (TMPRSS2), and etc.). ${ }^{3}$ An important sub-group belonging to these antivirals is the fluorine-containing drugs, including Paxlovid - the first oral tablet for the treatment of COVID-19. Until March 2022, there are already over 15 different types of fluorinated anti-COVID-19 drugs have been reported, counting for $>20 \%$ of the total drugs in the market for the treatment of COVID-19. An important consideration 
of inclusion of fluorine is to increase the drug's selectivity, enable it to dissolve in fats, and decrease the speed at which the drug is metabolized, thus allowing it more time to work.

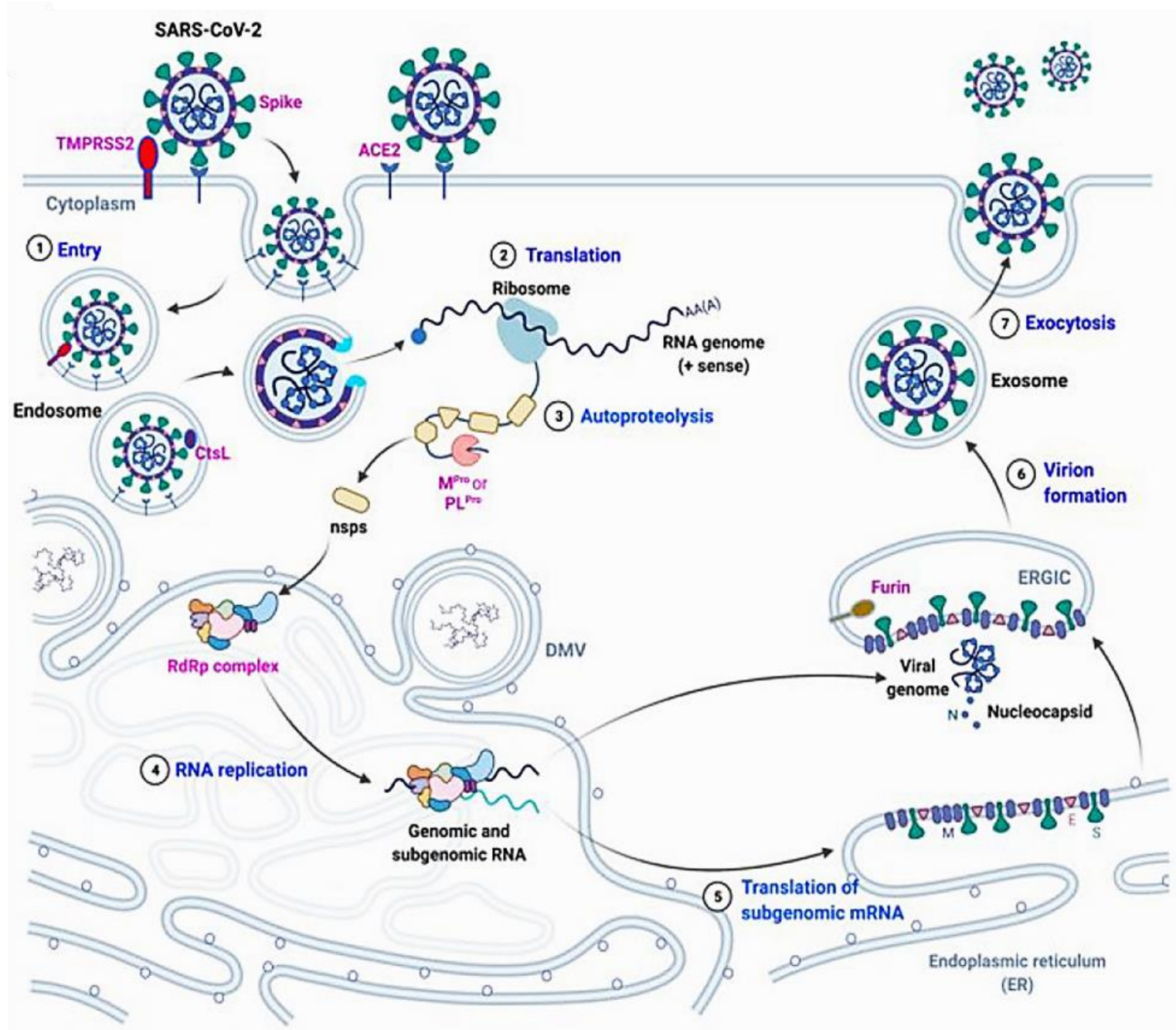

Figure 1. Cartoon diagram illustrating the life cycle of SARS-CoV-2. Seven sequential steps are labeled in blue. Proteins that are labeled in pink are targets for the development of antivirals. TMPRSS2, CtsL, and furin are three host proteases that prime Spike for viral entry and new virion packaging. Reproduced with permission from ref 5. Copyright 2022 American Chemical Society.

An increasing number of studies by our and other groups have shown that the inclusion of fluorinated segments in therapeutic agents has great potential to advance the performance of drugs. ${ }^{6-}$ 18 This review will provide an update on the progress of fluorine-containing drugs that has been recently made in clinical trials to combat COVID-19. A detailed discussion regarding the role of fluorine in advancing the performance of antiviral drugs against SARS-CoV-2 will be included. 
Finally, an outlook for the future discovery of new fluorinated drugs to treat COVID-19 will be provided.

\section{Fluorinated anti-COVID-19 drugs}

Fluorine is absent in most biological systems, however, it has been widely used to tailor the biological behavior of drugs for the enhancement of therapeutic efficacy. ${ }^{12,17,19}$ Fluorine substitution productively influences the conformation, membrane permeability, metabolic pathways, and pharmacokinetic properties of certain drugs. ${ }^{20-22}$ It is notable that a number of blockbuster drugs contain fluorine with single $\boldsymbol{F}$, aromatic $\boldsymbol{F}, \boldsymbol{C F}_{3}$ or aliphatic $\boldsymbol{C F}_{2}$ substitution. ${ }^{23}{ }^{24}$ Fluorinecontaining drugs account for over $20 \%$ of the total pharmaceuticals market as reviewed by other and our groups. ${ }^{7,19,24-26}$ A wide range of therapeutic areas have been covered by these newly developed fluorinated pharmaceutical drugs, for example, the treatment of cancer (e.g. 5-fluorouracil; alpelisib (Piqray $\left.^{\mathrm{TM}}\right)$; selinexor $\left(\right.$ Xpovio $\left.^{\mathrm{TM}}\right)$ ), schizophrenia (e.g. lumateperone (Caplyta $\left.{ }^{\mathrm{TM}}\right)$ ), migraine (e.g. ubrogepant (Ulbrelvy $\left.{ }^{\mathrm{TM}}\right)$ ), rheumatoid arthritis (e.g. upadacitinib (Rinvoq $\left.{ }^{\mathrm{TM}}\right)$ ), tuberculosis (e.g. pretomanid (PA-824)), and more recently for curing COVID-19.

\subsection{Inhibitors of main viral targets (Mpro or RdRp)}

\subsubsection{Paxlovid (Mpro)}

On December 22 2021, the U.S. Food and Drug Administration (FDA) issued an emergency use authorization for Paxlovid (Pfizer) for treating people with mild-to-moderate COVID-19 who have a high risk of progressing to severe disease, reducing admissions to hospital, intensive care unit and potential death. It is the first treatment for COVID-19 that is in the form of a pill and can be taken orally - a major step forward in the fight against COVID-19. Paxlovid consists of nirmatrelvir (PF07321332), a fluorinated oral drug containing a $\boldsymbol{C F}_{\mathbf{3}}$ group which inhibits the viral $\mathbf{M}^{\text {pro }}$ protease of SARS-CoV-2 to stop the virus from replicating, as well as ritonavir (Figure 2), which helps to maintain the high concentration of nirmatrelvir for a long period. ${ }^{2,3}$ Although COVID-19 cases are currently treated using a comprehensive approach of anticoagulants, oxygen, and antibiotics, the novel Paxlovid can significantly reduce hospitalization time and death rates. Trial results released by 
the manufacturer show that Paxlovid reduced risk of hospitalization or death for high-risk patients by $89 \%$ and $88 \%$ compared with the placebo, if given within three and five days of symptom onset, respectively. ${ }^{27}$ Impressively, the half-maximal effective concentration (EC50) for PF-0732133 is surprising low at $0.077 \mu \mathrm{M}$ (Table 1). ${ }^{28}$

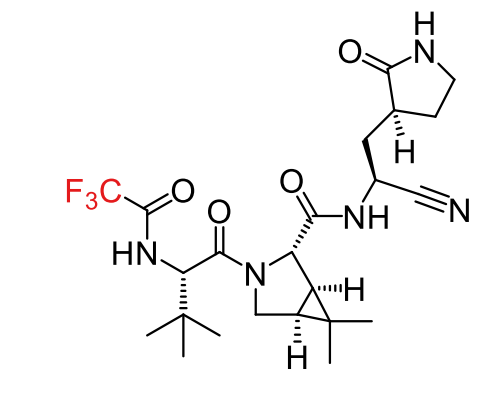

Paxlovid (PF-07321332, nirmatrelvir)

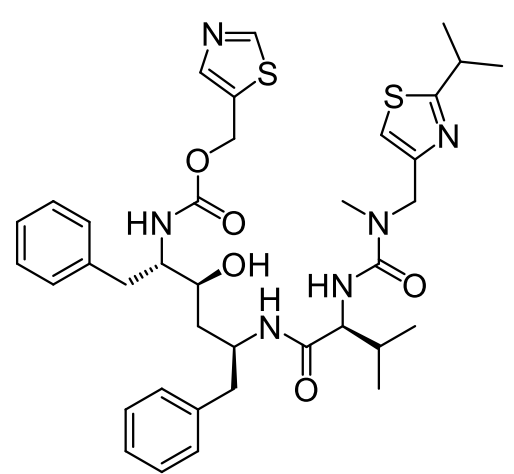

Paxlovid (Ritonavir)

Figure 2. Chemical structures of Paxlovid containing PF-0732133 and ritonavir.

\subsubsection{S-217622 (Mpro)}

S-217622 is an antiviral drug developed by Shionogi in partnership with Hokkaido University (Figure 3). It is the first non-peptidic, non-covalent SARS-CoV-2 $\mathrm{M}^{\text {pro }}$ inhibitor clinical candidate for treating COVID-19. ${ }^{29}$ It was discovered via virtual screening followed by biological screening of an in-house compound library, and optimization of the hit compound using a structure-based drugdesign strategy. S-217622 exhibited antiviral activity against a range of current outbreaking SARSCoV-2 variants and coronavirus families. The drug has favorable pharmacokinetic profiles in vivo for once-daily oral dosing for the treatment of COVID-19 infection. To be more specific, S-217622 shows a biochemical activity of $\mathrm{IC}_{50}=0.013 \mu \mathrm{M}$, an antiviral activity of $\mathrm{EC}_{50}=0.37 \mu \mathrm{M}$ (serine 2 gene-overexpressed VeroE6 cells), and preferable drug metabolism and pharmacokinetics profiles for oral dosing in rats (e.g. high metabolic stability: $96 \%$ and $88 \%$ in human and rat liver microsomes, respectively, and high oral absorption at 97\%). Furthermore, S-217622 shows low clearance rate with long half-lives ( $t_{1 / 2} \approx 10$ and $30 \mathrm{~h}$ in monkeys and dogs, respectively), suggesting its potential use for once-daily treatment of COVID-19 without requiring a pharmacokinetics booster such as ritonavir. It has been recently tested to be effective against the recently emerged Omicron variant. ${ }^{30}$ 


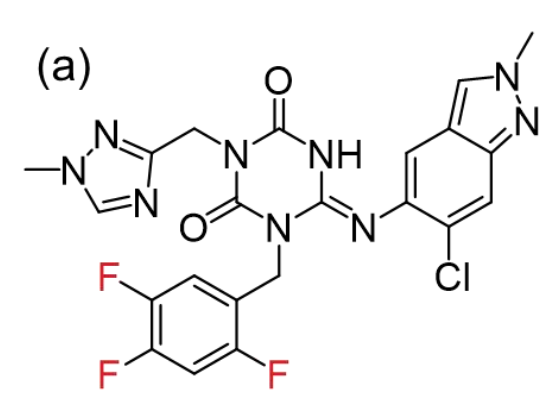

S-217622

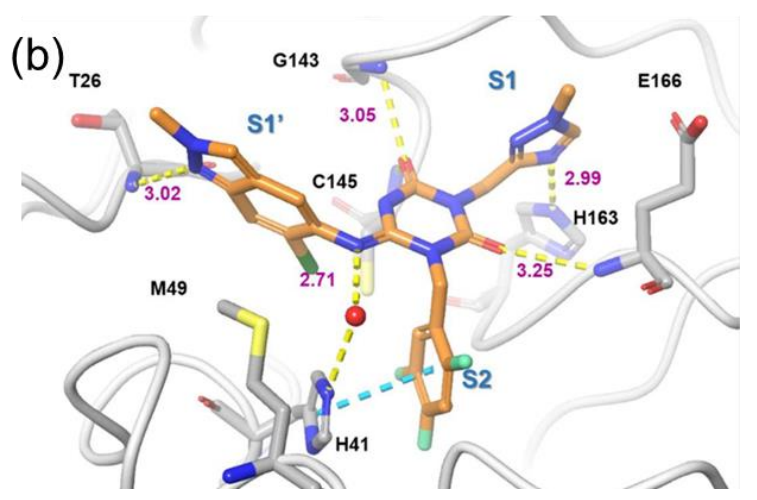

Figure 3. (a) Chemical structure of S-217622 and (b) its X-ray crystal co-structure with $\mathrm{M}^{\text {pro }}$ protease. S-217622 is colored in orange and the protein is colored in gray; water molecules are shown as red spheres; hydrogen bonds are indicated as yellow dashed lines; $\pi$ - $\pi$ stacking is indicated as a cyan dashed line. Reproduced with permission from ref 29. Copyright $2022 .{ }^{29}$

\subsubsection{Favipiravir (RdRp)}

Favipiravir (T-705, Figure 4), a fluorinated purine nucleic acid analogue, is one of the anti-COVID19 candidates considered in several clinical trials. ${ }^{31}$ It is a synthetic prodrug, first discovered by the Japanese company Toyoma, as a backup choice for resistant influenza infection. ${ }^{31,}{ }^{32}$ It has shown broad-spectrum activity against variety of RNA viruses including influenza, arenaviruses, bunyaviruses, and flaviviruses. ${ }^{33}$ In 2020, favipiravir was first used against SARS-CoV-2 in Wuhan at the very epicenter of the pandemic for the treatment of patients with mild to moderate COVID-19 disease. Favipiravir is an inhibitor of RdRp of the SARS-CoV-2 virus. ${ }^{34}$ It is metabolized intracellularly into its active phosphoribosylated metabolite (favipiravir-RTP, Figure 4), selective inhibiting viral RNA polymerase activity and prevents replication of the viral genome. ${ }^{31,32}$ However, the outcomes of clinical studies of favipiravir for the treatment of COVID-19 were conflicting. In July 2020, a clinical study by Fujita Health University showed that favipiravir has failed to demonstrate a clear efficacy in treating coronavirus patients at an early stage of the disease. Additional clinical studies are needed before it can confirm the effectiveness of using favipiravir for the treatment of COVID-19. There are currently 39 studies registered on clinicaltrials.gov to assess the utility of this drug in the management of COVID-19 (19 completed, 10 recruiting). 


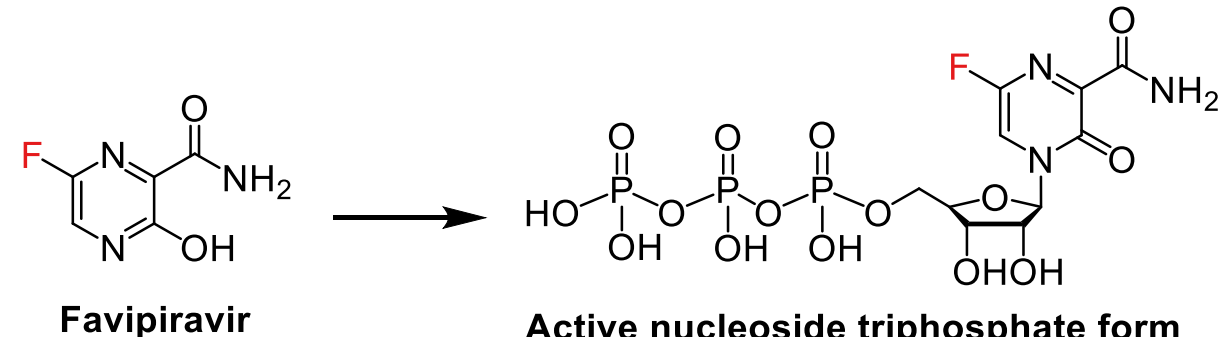

Figure 4. Chemical structures of favipiravir (T-705) and its active phosphoribosylated form.

\subsubsection{4'-Fluorouridine (RdRp)}

4'-Fluorouridine (4'-FIU, EIDD-2749, Figure 5) was invented by Plemper et al. in 2022 by 4'-fluorine substitution of molnupiravir. ${ }^{35}$ Molnupiravir (Figure 5) has been recently granted emergency use authorization by the US FDA. The focus on 4'-fluorine ribose substitutions was motivated by the small atomic radius and strong stereoelectronic effect of fluorine that can influence backbone conformation flexibility, which may lead to improved selectivity indices, increased lipophilicity, and greater metabolic stability. These properties obtained using fluorination define 4'-FIU as a broadspectrum candidate for the treatment of SARS-CoV-2, and related RNA virus infections. Unlike the Paxlovid inhibits the SARS-CoV-2 Mpro, 4'-FIU targets the RNA-dependent RNA polymerase-the same enzyme targeted by Merck's oral antiviral molnupiravir. However, the mechanism of 4'-FIU is distinct from molnupiravir. Molnupiravir introduces errors in the viral replication process, which produces mutants of the virus that are not viable, while 4'-FIU causes the polymerase to stall so the virus's genome doesn't get copied. ${ }^{35}$ As shown in Figure 4, 4'-FIU-TP is the bioactive 5'-triphosphate form of 4'-FlU. The study by Plemper et al. also shows that 4'-FIU was effective with a single daily dose, while molnupiravir must be taken twice daily. 4'-FIU was effective at fighting SARS-CoV-2 12 and $24 \mathrm{~h}$ after initial infection with the virus in tests with ferrets and mice, respectively, corresponding to several days post-infection in human. 
<smiles>C=C(OCC(O)C(O)C(O)C(C)C)n1ccc(NO)nc1=O</smiles>

Molnupiravir<smiles>CC(C)CC(O)C1OC(O)(CO)C1n1ccc(=O)[nH]c1=O</smiles>

4'-FIU<smiles>O=c1ccn(C2OC(O)(COP(=O)(O)OP(=O)(O)OP(=O)(O)O)C(O)C2(F)F)c(=O)[nH]1</smiles>

4'-FIU-TP

Figure 5. Chemical structures of molnupiravir, 4'-FIU and its bioactive 5'-triphosphate form 4'-FIUTP.

\subsubsection{AT-527 (RdRp)}

AT-527 is an orally administered double prodrug of a guanosine nucleotide analog, and has previously demonstrated in vitro and in vivo antiviral activity against several enveloped singlestranded RNA viruses, including human flaviviruses and coronaviruses SARS-CoV-2. ${ }^{36}$ This highly selective purine nucleotide prodrug was designed to uniquely inhibit RdRp, an enzyme that is essential for the replication of RNA viruses. The active triphosphate metabolite of AT-527, AT-9010, which cannot penetrate to cell membranes and is formed only after intracellular delivery of the prodrug (Figure 6). In normal human airway epithelial cells, the concentration of the drug required to inhibit replication of SARS-CoV-2 by $90 \%$ (EC90) is $0.47 \mu \mathrm{M}$ and has a maximum concentration of $0.64 \mu \mathrm{M}$ after oral administration by nonhuman primates (Table 1) ${ }^{33}$ AT-527 is not yet licensed or approved for any indication in the United States or any other country. In October 2021, Atea announced that AT-527 failed to meet the primary goal of the international Phase II MOONSONG clinical trial in subjects with mild or moderate COVID-19 in the outpatient setting.<smiles>CNc1nc(N)nc2c1ncn2C1OC(COP(=O)(N[C@@H](C)C(=O)OC(C)C)Oc2ccccc2)[C@@H](O)[C@H]1C(F)(F)F</smiles>

AT-527

AT-9010

Figure 6. Chemical structures of AT-527 and its active triphosphate metabolite AT-9010. 


\subsubsection{Sofosbuvir (RdRp)}

Sofosbuvir is a direct-acting antiviral agent and serves as an RdRp inhibitor (Figure 7). It was firstly approved for the treatment of Hepatitis C virus (HCV) infection in $2013 .{ }^{37}$ In 2020, Sadeghi et al. ${ }^{38}$ reported encouraging results from a clinical trial using sofosbuvir and daclatasvir as a potential combination treatment for moderate or severe COVID-19 patients. In this study, 66 patients were recruited and allocated to either the treatment arm or the control arm ( $n=33$ each group). These results show that sofosbuvir and daclatasvir combination treatment increased 14-day clinical recovery rates ( $88 \%$ vs. $67 \%)$ and reduced the length of hospital stays (6 days vs. 8 days). Another report by Ju et al. demonstrates for the first time that the active triphosphate form (sofosbuvir-TP, Figure 7) not only serves as an efficient terminator of the RdRp, but it terminates RNA confers a substantial level of resistance to excision by exonuclease. Sofosbuvir is removed at a lower rate by the SARSCoV-2 exonuclease complex compared with remdesivir (the first anti-COVID-19 drugs approved by FDA, administered via injection into a vein, Figure 7) upon incorporation of the triphosphate form of Sofosbuvir into RNA by the SARS-CoV-2 RdRp. Sofosbuvir inhibits SARS-CoV-2 replication in human hepatoma-derived (Huh-2) and Type II pneumocyte-derived (Calu-3) cells with EC50 values of 6.2 and $9.5 \mu \mathrm{M}$, respectively. ${ }^{39}$

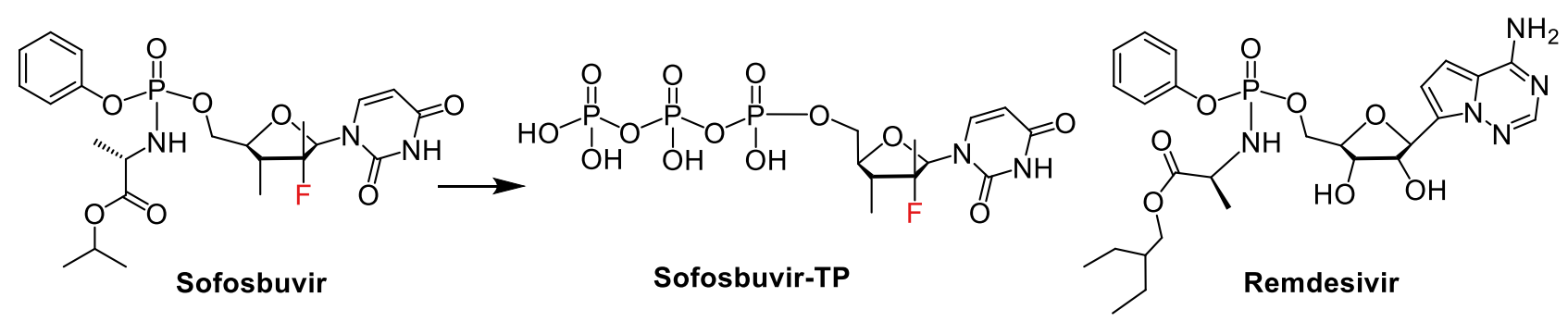

Figure 7. Chemical structures of sofosbuvir and its active triphosphate form sofosbuvir-TP. The chemical structure of related purine nucleotide remdesivir is also shown.

\subsection{Inhibitors of virus entry into cells}

SARS-CoV-2 uses the SARS-CoV receptor angiotensin-converting enzyme 2 (ACE2) for cell entry through its receptor-binding domain (RBD) and the serine protease transmembrane protease, serine 2 (TMPRSS2) for viral spike protein priming. ${ }^{40,41}$ Therefore, drugs act as TMPRSS2 inhibitors could 
potentially block the entry and might constitute a treatment option. A number of drugs have been demonstrated to be effective to SARS-CoV-2 infection, including mefloquine, proxalutamide, and etc..

\subsubsection{Mefloquine $\mathrm{HCl}$}

Mefloquine (MFQ) is a fluorinated derivative of hydroxychloroquine (HCQ) originally used for antimalarial therapy and prophylaxis (Figure 8). ${ }^{42}$ It was identified as a potential drug to effectively treat patients with COVID-19 by Watashi and coworkers from the Tokyo University of Science and collaborating institutions in Japan in $2021{ }^{43}$ After fluorination, MFQ performs a higher anti-SARSCoV-2 activity than HCQ in several SARS-CoV-2 infection models, such as the serine 2 geneoverexpressed VeroE6 cells $\left(\mathrm{EC}_{50}=1.28\right.$ vs. $1.94 \mu \mathrm{M} ; \mathrm{EC}_{90}=2.31$ vs. $\left.7.96 \mu \mathrm{M}\right)$ and human lungderived Calu-3 cells. MFQ serves as an anti-SARS-CoV-2 entry inhibitor and can effectively inhibits the viral entry process.<smiles>OC(c1cc(C(F)(F)F)nc2c(C(F)(F)F)cccc12)[C@H]1CCCCN1</smiles>

Mefloquine $\mathrm{HCl}$<smiles>[R]CCN(CC)CCCC(C)Nc1ccnc2cc(Cl)ccc12</smiles>

$\mathbf{R}=\mathrm{OH}$, Hydroxychloroquine $\mathbf{R}=\mathbf{H}$, Chloroquine

Figure 8. Chemical structures of mefloquine, hydroxychloroquine and chloroquine. Mefloquine is a fluorinated derivative of hydroxychloroquine and chloroquine, exhibiting enhanced anti-COVID-19 activities.

\subsubsection{Proxalutamide}

Proxalutamide (GT0918, Figure 9) is a second-generation non-steroidal androgen receptor (AR) antagonist. It has a dual mechanism of action in suppressing AR and was primarily developed for treatment of castration-resistant prostate cancer. In addition to direct AR antagonism, proxalutamide also acts as a suppressor of AR gene expression and regulates ACE2, a receptor of the new coronavirus SARS-CoV-2 entering the host cells, which would be beneficial for preventing the entry 
of SARS-CoV-2 into lung cells. ${ }^{44}$ Goren, Zimerman and coworkers have previously reported their preliminary analysis of the effects of proxalutamide in COVID-19 patients by taking $200 \mathrm{mg}$ per day. The results are encouraging and show an overall $74 \%$ reduction in nasopharyngeal detection of SARS-CoV-2 on the day seven of treatment. ${ }^{44}$ In a later study from the same group, a randomized, double-blinded, placebo-controlled clinical trial was conducted at two outpatient centers at Brasilia in Brazil. ${ }^{45}$ It was demonstrated that proxalutamide can reduce the hospitalization rate in treated men by $91 \%$ compared to usual care.

\subsection{Other fluorinated drugs}

Several other fluorinated drugs having the same or different mechanisms as above in the treatment of SARS-CoV-2 infection have been invented and studied, including halofantrine ( $\mathrm{M}^{\text {pro }}$ inhibitor), ralimetinib (LY2228820, p38 mitogen-activated protein kinase inhibitor), L-796568 ( $\beta$-3 adrenergic receptor agonist), dexamethasone (anti-flammatory), fluvoxamine (selective serotonin reuptake inhibitor), and etc.. Figure 9 and Table 1 summarize the chemical structures and anti-COVID-19 activities of these drugs.

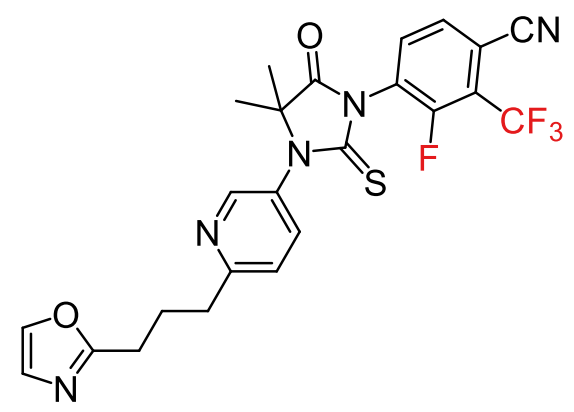

Proxalutamide

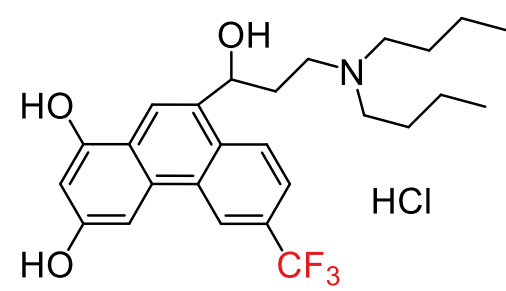

Halofantrine $\mathrm{HCl}$

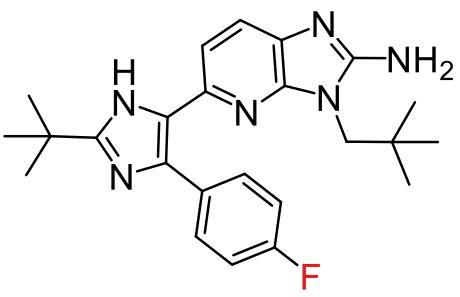

LY2228820

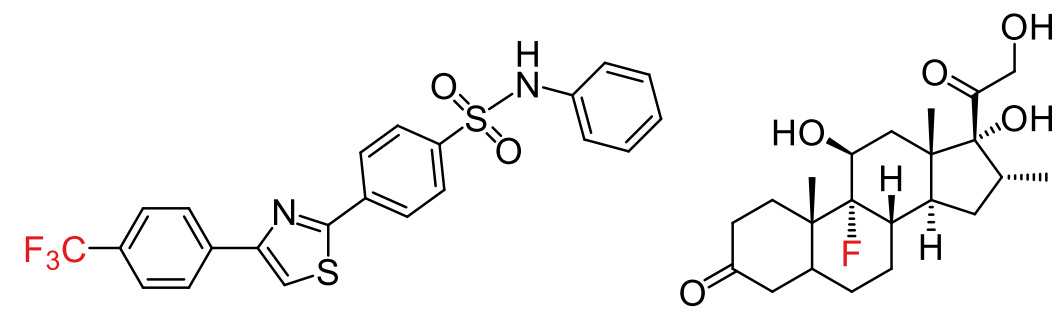

L-796568

Dexamethasone<smiles>COCCCC/C(=N\OCCN)c1ccc(C(F)(F)F)cc1</smiles>

Fluvoxamine

Figure 9. Chemical structures of other fluorinated anti-COVID-19 oral drugs.

Table 1. Summary of attractive fluorinated oral drugs with activity and selectivity to SARS-CoV-2. 


\begin{tabular}{|c|c|c|c|c|c|c|}
\hline \multirow[b]{2}{*}{ Name } & \multirow{2}{*}{$\begin{array}{l}\text { Molecular } \\
\text { weight }(\mathrm{g} / \mathrm{mol})\end{array}$} & \multirow[b]{2}{*}{ Mechanism } & \multicolumn{2}{|l|}{ PK Exposure } & \multirow{2}{*}{$\begin{array}{l}\text { SARS-CoV-2 } \\
\mathrm{EC}_{50}(\mu \mathrm{M})\end{array}$} & \multirow[b]{2}{*}{ Ref } \\
\hline & & & \begin{tabular}{|l|} 
Approx. \\
$C_{\max }(\mu \mathrm{M})$
\end{tabular} & $\begin{array}{l}\text { Approx. } \\
t_{1 / 2}(\mathrm{~h})\end{array}$ & & \\
\hline Paxlovid & 499.54 & $\mathrm{M}^{\text {pro }}$ inhibitor & $\begin{array}{l}1.6 \text { (human } \\
\text { oral, } 200 \\
\mathrm{mg} \text { ) }\end{array}$ & 7.7 & 0.077 & 28,46 \\
\hline S-217622 & 531.88 & $\mathrm{M}^{\text {pro }}$ inhibitor & $\begin{array}{l}254 \\
\text { (hamsters } \\
\text { oral, } 100 \\
\mathrm{mg} / \mathrm{kg} \text { ) }\end{array}$ & $\begin{array}{l}10 \\
\text { (monkey } \\
\text { ) and } 30 \\
\text { (dogs) }\end{array}$ & $0.29-0.50$ & 29,47 \\
\hline Favipiravir & 157.10 & RdRp inhibitor & $\begin{array}{l}400 \\
\text { (human } \\
\text { oral, } \\
200 \mathrm{mg} \text { ) }\end{array}$ & $2-5.5$ & 61.88 & $\begin{array}{l}32,48- \\
50\end{array}$ \\
\hline 4'-Fluorouridine & 246.19 & RdRp inhibitor & $\begin{array}{l}63.3 \text { (ferrets } \\
\text { oral, } 50 \\
\mathrm{mg} / \mathrm{kg} \text { ) }\end{array}$ & 9.7 & $0.61-1.2$ & 35 \\
\hline AT-527 & 581.54 & RdRp inhibitor & $\begin{array}{l}0.64 \\
\text { (Nonhuman } \\
\text { primates) }\end{array}$ & 0.7 & $0.47\left(\mathrm{EC}_{90}\right)$ & 36 \\
\hline Sofosbuvir & 529.46 & RdRp inhibitor & $\begin{array}{l}1.1 \text { (human } \\
\text { oral) }\end{array}$ & $>24$ & 6.2 & 51 \\
\hline Mefloquine & 378.31 & $\begin{array}{l}\text { TMPRSS2 } \\
\text { inhibitor }\end{array}$ & $\begin{array}{l}4.58 \\
\text { (human } \\
\text { oral) }\end{array}$ & $>400$ & 2.31 & $\begin{array}{l}43,52, \\
53\end{array}$ \\
\hline Proxalutamide & 517.50 & $\begin{array}{l}\text { ACE2 and } \\
\text { TMPRSS2 } \\
\text { inhibitor }\end{array}$ & $\begin{array}{l}\text { 27 (human } \\
\text { oral, } 100 \\
\text { mg) }\end{array}$ & 21.1 & $\begin{array}{l}\text { Not } \\
\text { applicable }\end{array}$ & 44,54 \\
\hline Halofantrine & 500.42 & $\mathrm{M}^{\text {pro }}$ inhibitor & $\begin{array}{l}1.0 \text { (human } \\
\text { oral) }\end{array}$ & 58 & 0.33 & 55,56 \\
\hline $\begin{array}{l}\text { Ralimetinib } \\
\text { (LY2228820) }\end{array}$ & 420.54 & $\begin{array}{l}\text { p38 mitogen- } \\
\text { activated } \\
\text { protein kinase } \\
\text { inhibitor }\end{array}$ & $\begin{array}{l}5.0 \text { (human, } \\
\text { oral) }\end{array}$ & 190 & 1.75 & 57 \\
\hline L-796568 & 697.62 & $\begin{array}{l}\beta-3 \text { adrenergic } \\
\text { receptor } \\
\text { agonist }\end{array}$ & $\begin{array}{l}0.3 \mu \mathrm{M} \\
\text { (dog, oral) }\end{array}$ & 13 & 1.15 & 58 \\
\hline Dexamethasone & 392.46 & \begin{tabular}{|l|} 
anti- \\
inflammatory
\end{tabular} & $\begin{array}{l}\text { Not } \\
\text { applicable }\end{array}$ & $\sim 3$ & $\begin{array}{l}\text { Not } \\
\text { applicable }\end{array}$ & 59,60 \\
\hline Fluvoxamine & 318.34 & $\begin{array}{l}\text { Selective } \\
\text { serotonin } \\
\text { reuptake } \\
\text { inhibitor } \\
\end{array}$ & $\begin{array}{l}0.6 \text { (human } \\
\text { oral, } 60 \mathrm{mg} \\
\text { daily) }\end{array}$ & $\sim 80$ & 0.69 & 61 \\
\hline
\end{tabular}

\section{Conclusions}

Fluorinated compounds are very successful in the long history of medicinal chemistry. Fluorine has both hydrophobic and lipophobic characters, ${ }^{21,25,62,63}$ and the judicious introduction of fluorine into 
a drug can productively improve its membrane permeability and cellular uptake, influence pharmacokinetic properties, and subsequently increase the therapeutic efficacy of SARS-CoV-2. Fluorinated oral drugs appear to be an important new weapon for the treatment of COVID-19 due to the superior antiviral performance compared with the non-fluorinated analogues. It may be predicted that the number of anti-COVID-19 fluorinated drugs on the market will continue to increase.

While it is exciting to see the rapid discovery and investigation of many new oral drugs for COVID-19, prevention and vaccination are still the best strategy. COVID antivirals are an important complement to vaccines, and they serve an important function. The main reason not to rely only on the new pills is that antiviral medications, which stop the virus from replicating in the body, must be taken in a narrow window at the early phases of COVID-19. Antiviral drugs are not going to provide much benefit once a shortness of breath or other serious symptoms has been developed.

\section{Author Information}

\section{Corresponding Authors}

Cheng Zhang - Australian Institute for Bioengineering and Nanotechnology, University of Queensland, Brisbane, Queensland 4072, Australia; ARC Centre of Excellence in Convergent BioNano Science and Technology, University of Queensland, Brisbane, Queensland 4072, Australia; Materials Research Laboratory, University of California, Santa Barbara, California 93106, United States. orcid.org/0000-0002-2722-7497; Email: c.zhang3@uq.edu.au

\section{Biographies}

Dr Cheng Zhang is a National Health and Medical Research Council (NHMRC) Early Career Fellow at the Australian Institute for Bioengineering and Nanotechnology (AIBN), The University of Queensland (UQ) where he leads the research in fluoropolymers. He received his Bachelor degree from Yantai University and Master degree from Harbin Institute of Technology before he came to UQ in 2012 as a PhD student. He obtained his PhD degree in 2016 in Biomedical Engineering under supervision of Professor Andrew K. Whittaker. From 2016 to 2018, he was a postdoctoral research 
fellow in the Whittaker group to develop advanced medical imaging agents. In 2019, he was awarded an NHMRC Fellowship and relocated to UCSB working with Professor Craig J. Hawker, Professor Christopher M. Bates and Professor Glenn H. Fredrickson on block copolymer chromatography separation and self-assembly projects. His research focuses on the development of advanced polymerization, purification and characterization techniques to prepare well-defined functional polymers with precisely-tailored properties for important applications from PFAS remediation, energy materials e.g. solid electrolytes to functional biomaterials e.g. imaging and therapeutic agents.

\section{Acknowledgements}

C.Z. acknowledges support from the National Health and Medical Research Council for an Early Career Fellowship (APP1157440 to C.Z.).

\section{References}

1. Cao, W.; Cho, C.-C. D.; Geng, Z. Z.; Shaabani, N.; Ma, X. R.; Vatansever, E. C.;

Alugubelli, Y. R.; Ma, Y.; Chaki, S. P.; Ellenburg, W. H.; Yang, K. S.; Qiao, Y.; Allen, R.;

Neuman, B. W.; Ji, H.; Xu, S.; Liu, W. R. Evaluation of SARS-CoV-2 Main Protease Inhibitors

Using a Novel Cell-Based Assay. ACS Cent. Sci. 2022.

2. Reported Cases and Deaths by Country or Territory: https://www.worldometers.info/coronavirus/.

3. Drożdżal, S.; Rosik, J.; Lechowicz, K.; Machaj, F.; Szostak, B.; Przybyciński, J.; Lorzadeh, S.; Kotfis, K.; Ghavami, S.; Łos, M. J. An update on drugs with therapeutic potential for SARSCoV-2 (COVID-19) treatment. Drug Resist. Updat. 2021, 59, 100794.

4. Https://ourworldindata.org/covid-vaccinations.

5. Fan, H.; Lou, F.; Fan, J.; Li, M.; Tong, Y. The emergence of powerful oral anti-COVID-19 drugs in the post-vaccine era. Lancet Microbe 2022, 3, e91.

6. Inoue, M.; Sumii, Y.; Shibata, N. Contribution of Organofluorine Compounds to Pharmaceuticals. ACS Omega 2020, 5, 10633-10640. 
7. Purser, S.; Moore, P. R.; Swallow, S.; Gouverneur, V. Fluorine in medicinal chemistry. Chem. Soc. Rev. 2008, 37, 320-330.

8. Zhang, C.; Moonshi, S. S.; Han, Y.; Puttick, S.; Peng, H.; Magoling, B. J. A.; Reid, J. C.; Bernardi, S.; Searles, D. J.; Král, P.; Whittaker, A. K. PFPE-Based Polymeric 19F MRI Agents: A New Class of Contrast Agents with Outstanding Sensitivity. Macromolecules 2017, 50, 5953-5963.

9. Moonshi, S. S.; Zhang, C.; Peng, H.; Puttick, S.; Rose, S.; Fisk, N. M.; Bhakoo, K.; Stringer, B. W.; Qiao, G. G.; Gurr, P. A.; Whittaker, A. K. A Unique (19)F MRI Agent for the Tracking of Non Phagocytic Cells In Vivo. Nanoscale 2018, 10, 8226-8239.

10. Zhang, C.; Ferenz, K. B. Nano-Bio-Imaging and Therapeutic Nanoparticles. J. Nanosci. Nanomed. 2018, 2, 19-20.

11. Zhang, C.; Kim, D. S.; Lawrence, J.; Hawker, C. J.; Whittaker, A. K. Elucidating the Impact of Molecular Structure on the 19F NMR Dynamics and MRI Performance of Fluorinated Oligomers. ACS Macro Lett. 2018, 7, 921-926.

12. Zhang, C.; Moonshi, S. S.; Wang, W.; Ta, H. T.; Han, Y.; Han, F. Y.; Peng, H.; Kral, P.; Rolfe, B. E.; Gooding, J. J.; Gaus, K.; Whittaker, A. K. High F-Content Perfluoropolyether-Based Nanoparticles for Targeted Detection of Breast Cancer by (19)F Magnetic Resonance and Optical Imaging. ACS Nano 2018, 12, 9162-9176.

13. Zhang, C.; Sanchez, R. J. P.; Fu, C.; Clayden-Zabik, R.; Peng, H.; Kempe, K.; Whittaker, A. K. Importance of Thermally Induced Aggregation on (19)F Magnetic Resonance Imaging of Perfluoropolyether-Based Comb-Shaped Poly(2-oxazoline)s. Biomacromolecules 2019, 20, 365374.

14. Önal, E.; Zhang, C.; Davarcı, D.; İșci, Ü.; Pilet, G.; Whittaker, A. K.; Dumoulin, F. Cyclotriphosphazene, A Scaffold for 19F MRI Contrast Agents. Tetrahedron Lett. 2018, 59, 521523.

15. Zhang, C.; Li, L.; Han, F. Y.; Yu, X.; Tan, X.; Fu, C.; Xu, Z. P.; Whittaker, A. K. Integrating Fluorinated Polymer and Manganese-Layered Double Hydroxide Nanoparticles as pH- 
activated 19F MRI Agents for Specific and Sensitive Detection of Breast Cancer. Small 2019, 15, e1902309.

16. Fu, C.; Yu, Y.; Xu, X.; Wang, Q.; Chang, Y.; Zhang, C.; Zhao, J.; Peng, H.; Whittaker, A. K. Functional Polymers as Metal-free Magnetic Resonance Imaging Contrast Agents. Prog. Polym. Sci. 2020, 108, 101286.

17. Zhang, C.; Liu, T.; Wang, W.; Bell, C. A.; Han, Y.; Fu, C.; Peng, H.; Tan, X.; Kral, P.; Gaus, K.; Gooding, J. J.; Whittaker, A. K. Tuning of the Aggregation Behavior of Fluorinated Polymeric Nanoparticles for Improved Therapeutic Efficacy. ACS Nano 2020, 14, 7425-7434.

18. Usman, A.; Zhang, C.; Zhao, J.; Peng, H.; Kurniawan, N. D.; Fu, C.; Hill, D. J. T.;

Whittaker, A. K. Tuning the thermoresponsive properties of PEG-based fluorinated polymers and stimuli responsive drug release for switchable $19 \mathrm{~F}$ magnetic resonance imaging. Polym. Chem. 2021, 12, 5438-5448.

19. Zhang, C.; Yan, K.; Fu, C.; Peng, H.; Hawker, C. J.; Whittaker, A. K. Biological Utility of Fluorinated Compounds: from Materials Design to Molecular Imaging, Therapeutics and Environmental Remediation. Chem. Rev. 2022, 122, 167-208.

20. Mei, H.; Han, J.; Klika, K. D.; Izawa, K.; Sato, T.; Meanwell, N. A.; Soloshonok, V. A. Applications of fluorine-containing amino acids for drug design. Eur. J. Med. Chem. 2020, 186, 111826.

21. Clayden, J. Fluorinated compounds present opportunities for drug discovery. Nature Publishing Group: 2019.

22. Park, B. K.; Kitteringham, N. R.; O'Neill, P. M. Metabolism of fluorine-containing drugs. Annu. Rev. Pharmacol. Toxicol. 2001, 41, 443-470.

23. Wang, J.; Sánchez-Roselló, M.; Aceña, J. L.; del Pozo, C.; Sorochinsky, A. E.; Fustero, S.; Soloshonok, V. A.; Liu, H. Fluorine in Pharmaceutical Industry: Fluorine-Containing Drugs Introduced to the Market in the Last Decade (2001-2011). Chem. Rev. 2014, 114, 2432-2506. 
24. Mei, H.; Han, J.; Fustero, S.; Medio-Simon, M.; Sedgwick, D. M.; Santi, C.; Ruzziconi, R.;

Soloshonok, V. A. Fluorine-Containing Drugs Approved by the FDA in 2018. Chem. Eur. J. 2019, $25,11797-11819$.

25. Gillis, E. P.; Eastman, K. J.; Hill, M. D.; Donnelly, D. J.; Meanwell, N. A. Applications of Fluorine in Medicinal Chemistry. J. Med. Chem. 2015, 58, 8315-8359.

26. Mei, H.; Remete, A. M.; Zou, Y.; Moriwaki, H.; Fustero, S.; Kiss, L.; Soloshonok, V. A.; Han, J. Fluorine-containing drugs approved by the FDA in 2019. Chin. Chem. Lett. 2020.

27. Burki, T. K. The role of antiviral treatment in the COVID-19 pandemic. Lancet Respir. Med. 2022, 10, e18.

28. Owen, D. R.; Allerton, C. M. N.; Anderson, A. S.; Aschenbrenner, L.; Avery, M.; Berritt, S.; Boras, B.; Cardin, R. D.; Carlo, A.; Coffman, K. J.; Dantonio, A.; Di, L.; Eng, H.; Ferre, R.; Gajiwala, K. S.; Gibson, S. A.; Greasley, S. E.; Hurst, B. L.; Kadar, E. P.; Kalgutkar, A. S.; Lee, J. C.; Lee, J.; Liu, W.; Mason, S. W.; Noell, S.; Novak, J. J.; Obach, R. S.; Ogilvie, K.; Patel, N. C.; Pettersson, M.; Rai, D. K.; Reese, M. R.; Sammons, M. F.; Sathish, J. G.; Singh, R. S. P.; Steppan, C. M.; Stewart, A. E.; Tuttle, J. B.; Updyke, L.; Verhoest, P. R.; Wei, L.; Yang, Q.; Zhu, Y. An oral SARS-CoV-2 M<sup>pro</sup> inhibitor clinical candidate for the treatment of COVID-19.

Science 2021, 374, 1586-1593.

29. Unoh, Y.; Uehara, S.; Nakahara, K.; Nobori, H.; Yamatsu, Y.; Yamamoto, S.; Maruyama, Y.; Taoda, Y.; Kasamatsu, K.; Suto, T. Discovery of S-217622, a Non-Covalent Oral SARS-CoV-2 3CL Protease Inhibitor Clinical Candidate for Treating COVID-19. bioRxiv 2022.

30. Uraki, R.; Kiso, M.; Imai, M.; Yamayoshi, S.; Ito, M.; Ujie, M.; Furusawa, Y.; IwatsukiHorimoto, K.; Sakai-Tagawa, Y.; Kawaoka, Y. Therapeutic efficacy of antibodies and antivirals against a SARS-CoV-2 Omicron variant. 2022.

31. Titova, Y. A.; Fedorova, O. V. Favipiravir - a Modern Antiviral Drug: Synthesis and Modifications. Chem. Heterocycl. 2020, 56, 659-662. 
32. Joshi, S.; Parkar, J.; Ansari, A.; Vora, A.; Talwar, D.; Tiwaskar, M.; Patil, S.; Barkate, H. Role of favipiravir in the treatment of COVID-19. Int. J. Infect. Dis. 2021, 102, 501-508.

33. YAVUZ, S.; Çelikyurt, F. I. K. An update of anti-viral treatment of COVID-19. Turk. J. Med. Sci. 2021, 51, 3372-3390.

34. Driouich, J.-S.; Cochin, M.; Lingas, G.; Moureau, G.; Touret, F.; Petit, P.-R.; Piorkowski, G.; Barthélémy, K.; Laprie, C.; Coutard, B.; Guedj, J.; de Lamballerie, X.; Solas, C.; Nougairède, A. Favipiravir antiviral efficacy against SARS-CoV-2 in a hamster model. Nat. Commun. 2021, 12, 1735.

35. Sourimant, J.; Lieber, C. M.; Aggarwal, M.; Cox, R. M.; Wolf, J. D.; Yoon, J. J.; Toots, M.; Ye, C.; Sticher, Z.; Kolykhalov, A. A.; Martinez-Sobrido, L.; Bluemling, G. R.; Natchus, M. G.; Painter, G. R.; Plemper, R. K. 4'-Fluorouridine is an oral antiviral that blocks respiratory syncytial virus and SARS-CoV-2 replication. Science 2022, 375, 161-167.

36. Good, S. S.; Westover, J.; Jung, K. H.; Zhou, X.-J.; Moussa, A.; La Colla, P.; Collu, G.; Canard, B.; Sommadossi, J.-P. AT-527, a Double Prodrug of a Guanosine Nucleotide Analog, Is a Potent Inhibitor of SARS-CoV-2 In Vitro and a Promising Oral Antiviral for Treatment of COVID19. Antimicrob. Agents Chemother. 2021, 65, e02479-20.

37. Nourian, A.; Khalili, H. Sofosbuvir as a potential option for the treatment of COVID-19. Acta Biomed. 2020, 91, 239.

38. Sadeghi, A.; Ali Asgari, A.; Norouzi, A.; Kheiri, Z.; Anushirvani, A.; Montazeri, M.; Hosamirudsai, H.; Afhami, S.; Akbarpour, E.; Aliannejad, R.; Radmard, A. R.; Davarpanah, A. H.; Levi, J.; Wentzel, H.; Qavi, A.; Garratt, A.; Simmons, B.; Hill, A.; Merat, S. Sofosbuvir and daclatasvir compared with standard of care in the treatment of patients admitted to hospital with moderate or severe coronavirus infection (COVID-19): a randomized controlled trial. J. Antimicrob. Chemother. 2020, 75, 3379-3385.

39. Sacramento, C. Q.; Fintelman-Rodrigues, N.; Temerozo, J. R.; de Paula Dias Da Silva, A.; da Silva Gomes Dias, S.; dos Santos da Silva, C.; Ferreira, A. C.; Mattos, M.; Pão, C. R. R.; de 
Freitas, C. S.; Soares, V. C.; Hoelz, L. V. B.; Fernandes, T. V. A.; Branco, F. S. C.; Bastos, M. M.; Boechat, N.; Saraiva, F. B.; Ferreira, M. A.; Rajoli, R. K. R.; Pedrosa, C. S. G.; Vitória, G.; Souza, L. R. Q.; Goto-Silva, L.; Guimarães, M. Z.; Rehen, S. K.; Owen, A.; Bozza, F. A.; Bou-Habib, D. C.; Bozza, P. T.; Souza, T. M. L. The <em>in vitro</em> antiviral activity of the anti-hepatitis C virus (HCV) drugs daclatasvir and sofosbuvir against SARS-CoV-2. bioRxiv 2020, 2020.06.15.153411.

40. Hoffmann, M.; Kleine-Weber, H.; Schroeder, S.; Krüger, N.; Herrler, T.; Erichsen, S.; Schiergens, T. S.; Herrler, G.; Wu, N.-H.; Nitsche, A.; Müller, M. A.; Drosten, C.; Pöhlmann, S. SARS-CoV-2 Cell Entry Depends on ACE2 and TMPRSS2 and Is Blocked by a Clinically Proven Protease Inhibitor. Cell 2020, 181, 271-280.e8.

41. Shang, J.; Wan, Y.; Luo, C.; Ye, G.; Geng, Q.; Auerbach, A.; Li, F. Cell entry mechanisms of SARS-CoV-2. Proc. Natl. Acad. Sci. U.S.A. 2020, 117, 11727-11734.

42. Sinha, S.; Medhi, B.; Sehgal, R. Challenges of drug-resistant malaria. Parasite 2014, 21. 43. Shionoya, K.; Yamasaki, M.; Iwanami, S.; Ito, Y.; Fukushi, S.; Ohashi, H.; Saso, W.; Tanaka, T.; Aoki, S.; Kuramochi, K.; Iwami, S.; Takahashi, Y.; Suzuki, T.; Muramatsu, M.; Takeda, M.; Wakita, T.; Watashi, K. Mefloquine, a Potent Anti-severe Acute Respiratory Syndrome-Related Coronavirus 2 (SARS-CoV-2) Drug as an Entry Inhibitor in vitro. Front. microbiol. 2021, 12.

44. Cadegiani, F. A.; McCoy, J.; Wambier, C. G.; Vaño-Galván, S.; Shapiro, J.; Tosti, A.; Zimerman, R. A.; Goren, A. Proxalutamide significantly accelerates viral clearance and reduces time to clinical remission in patients with mild to moderate COVID-19: results from a randomized, double-blinded, placebo-controlled trial. Cureus 2021, 13.

45. McCoy, J.; Goren, A.; Cadegiani, F. A.; Vaño-Galván, S.; Kovacevic, M.; Situm, M.; Shapiro, J.; Sinclair, R.; Tosti, A.; Stanimirovic, A.; Fonseca, D.; Dorner, E.; Onety, D. C.; Zimerman, R. A.; Wambier, C. G. Proxalutamide Reduces the Rate of Hospitalization for COVID- 
19 Male Outpatients: A Randomized Double-Blinded Placebo-Controlled Trial. Front. Med. 2021,

8.

46. Luttens, A.; Gullberg, H.; Abdurakhmanov, E.; Vo, D. D.; Akaberi, D.; Talibov, V. O.;

Nekhotiaeva, N.; Vangeel, L.; De Jonghe, S.; Jochmans, D.; Krambrich, J.; Tas, A.; Lundgren, B.;

Gravenfors, Y.; Craig, A. J.; Atilaw, Y.; Sandström, A.; Moodie, L. W. K.; Lundkvist, Å.; van

Hemert, M. J.; Neyts, J.; Lennerstrand, J.; Kihlberg, J.; Sandberg, K.; Danielson, U. H.; Carlsson, J.

Ultralarge Virtual Screening Identifies SARS-CoV-2 Main Protease Inhibitors with Broad-

Spectrum Activity against Coronaviruses. J. Am. Chem. Soc. 2022.

47. Sasaki, M.; Tabata, K.; Kishimoto, M.; Itakura, Y.; Kobayashi, H.; Ariizumi, T.; Uemura,

K.; Toba, S.; Kusakabe, S.; Maruyama, Y. Oral administration of S-217622, a SARS-CoV-2 main

protease inhibitor, decreases viral load and accelerates recovery from clinical aspects of COVID-19.

bioRxiv 2022.

48. Agrawal, U.; Raju, R.; Udwadia, Z. F. Favipiravir: A new and emerging antiviral option in COVID-19. Med. J. Armed. Forces India 2020, 76, 370-376.

49. Hassanipour, S.; Arab-Zozani, M.; Amani, B.; Heidarzad, F.; Fathalipour, M.; Martinez-deHoyo, R. The efficacy and safety of Favipiravir in treatment of COVID-19: a systematic review and meta-analysis of clinical trials. Sci. Rep. 2021, 11, 11022.

50. Shiraki, K.; Daikoku, T. Favipiravir, an anti-influenza drug against life-threatening RNA virus infections. Pharmacol. Ther. 2020, 209, 107512-107512.

51. Jockusch, S.; Tao, C.; Li, X.; Chien, M.; Kumar, S.; Morozova, I.; Kalachikov, S.; Russo, J. $\mathrm{J}$; Ju, J. Sofosbuvir terminated RNA is more resistant to SARS-CoV-2 proofreader than RNA terminated by Remdesivir. Sci. Rep. 2020, 10, 16577.

52. Rodrigues-Diez, R. R.; Tejera-Muñoz, A.; Marquez-Exposito, L.; Rayego-Mateos, S.; Santos Sanchez, L.; Marchant, V.; Tejedor Santamaria, L.; Ramos, A. M.; Ortiz, A.; Egido, J.; Ruiz-Ortega, M. Statins: Could an old friend help in the fight against COVID-19? Br. J. Pharmacol 2020, 177, 4873-4886. 
53. Desjardins, R.; Pamplin III, C.; Von Bredow, J.; Barry, K.; Canfield, C. Kinetics of a new antimalarial, mefloquine. Clin. Pharmacol. Ther. 1979, 26, 372-379.

54. Li, H.; Song, G.; Zhou, Q.; Ran, R.; Jiang, H.; Zhang, R.; Liu, Y.; Zhang, J.; Meng, L.; Ma, L.; Sun, Y.; Wang, M.; Zhou, Q.; Yan, H.; Zhou, Q.; Dong, X.; Tong, Y. Activity of preclinical and phase I clinical trial of a novel androgen receptor antagonist GT0918 in metastatic breast cancer. Breast Cancer Res. Treat. 2021, 189, 725-736.

55. Sarhan, A. A.; Ashour, N. A.; Al - Karmalawy, A. A. The journey of antimalarial drugs against SARS-CoV-2: Review article. Inform. Med. Unlocked 2021, 24, 100604.

56. In silico Potential of Approved Antimalarial Drugs for Repurposing Against COVID-19. OMICS J. Integr. Biol. 2020, 24, 568-580.

57. Patnaik, A.; Haluska, P.; Tolcher, A. W.; Erlichman, C.; Papadopoulos, K. P.; Lensing, J. L.; Beeram, M.; Molina, J. R.; Rasco, D. W.; Arcos, R. R.; Kelly, C. S.; Wijayawardana, S. R.; Zhang, X.; Stancato, L. F.; Bell, R.; Shi, P.; Kulanthaivel, P.; Pitou, C.; Mulle, L. B.; Farrington, D. L.; Chan, E. M.; Goetz, M. P. A First-in-Human Phase I Study of the Oral p38 MAPK Inhibitor, Ralimetinib (LY2228820 Dimesylate), in Patients with Advanced Cancer. Clin. Cancer Res. 2016, $22,1095-1102$.

58. Bakowski, M. A.; Beutler, N.; Chen, E.; Nguyen, T.-T. H.; Kirkpatrick, M. G.; Parren, M.; Yang, L.; Ricketts, J.; Gupta, A. K.; Hull, M. V.; Schultz, P. G.; Burton, D. R.; Chatterjee, A. K.; McNamara, C. W.; Rogers, T. F. Oral drug repositioning candidates and synergistic remdesivir combinations for the prophylaxis and treatment of COVID-19. bioRxiv 2020, 2020.06.16.153403. 59. Pilatti, G. L.; André dos Santos, F.; Bianchi, A.; Cavassim, R.; Tozetto, C. W. The Use of Celecoxib and Dexamethasone for the Prevention and Control of Postoperative Pain After Periodontal Surgery. J. Periodontol. 2006, 77, 1809-1814.

60. Patel, S. K.; Saikumar, G.; Rana, J.; Dhama, J.; Yatoo, M. I.; Tiwari, R.; RodríguezMorales, A. J.; Dhama, K. Dexamethasone: A boon for critically ill COVID-19 patients? Travel Med. Infect. Dis. 2020, 37, 101844-101844. 
61. Eugene, A. R. Fluoxetine pharmacokinetics and tissue distribution suggest a possible role in reducing SARS-CoV-2 titers. medRxiv 2020, 2020.12.17.20248442.

62. Tan, X.; Sawczyk, M.; Chang, Y.; Wang, Y.; Usman, A.; Fu, C.; Král, P.; Peng, H.; Zhang, C.; Whittaker, A. K. Revealing the Molecular-Level Interactions between Cationic Fluorinated Polymer Sorbents and the Major PFAS Pollutant PFOA. Macromolecules 2022.

63. Tan, X.; Zhong, J.; Fu, C.; Dang, H.; Han, Y.; Král, P.; Guo, J.; Yuan, Z.; Peng, H.; Zhang, C.; Whittaker, A. K. Amphiphilic Perfluoropolyether Copolymers for the Effective Removal of Polyfluoroalkyl Substances from Aqueous Environments. Macromolecules 2021, 54, 3447-3457. 